\title{
PENGARUH PENGGUNAAN LKPD TERHADAP KETERAMPILAN BERPIKIR KRITIS DAN HASIL BELAJAR PESERTA DIDIK KELAS XI IPA SMA NEGERI 6 MAROS (STUDI MATERI POKOK HIDROLISIS GARAM)
}

\author{
Amalia, Hasri ${ }^{1}$, Taty Sulastry ${ }^{2}$ \\ ${ }^{1,2}$ Dosen Program Pascasarjana Universitas Negeri Makassar \\ Email: amaliaj924@gmail.com
}

\begin{abstract}
ABSTRAK
Penelitian ini adalah penelitian eksperimen semu yang bertujuan untuk mengetahui pengaruh penggunaan LKPD terhadap keterampilan berpikir kritis dan hasil belajar kelas XI IPA SMA Negeri 6 Maros materi pokok hidrolisis garam. Desain penelitian Pretest Treatment Postest Design. Penentuan sampel dilakukan secara random kelas dan terpilih kelas XI IPA 1 sebagai kelas A dan kelas XI IPA 3 sebagai kelas B. Data dianalisis menggunakan analisis deskriptif dan uji independent sample T-Test. Hasil analisis deskriptif diperoleh rata-rata nilai keterampilan berpikir kritis dan hasil belajar belajar kelas A adalah 72,76 dan kelas B adalah 56,90 dengan standar deviasi masing-masing 15,46 dan 18,56. Data rata-rata nilai $\mathrm{N}$-gain indikator keterampilan berpikir kritis pada kelas A sebesar 0,625 berada dalam kategori sedang dan N-gain hasil belajar sebesar 0,70 berada dalam kategori tinggi. Sedangkan kelas B sebesar 0.454 dan 0,52 berada dalam kategori sedang. Hasil pengujian hipotesis dengan uji-t pada taraf signifikan, $\alpha=0,05$ diperoleh nilai $t_{\text {hitung }} 3,22>t_{\text {tabel }} 2,02$ dan signifikansi $(0,003<0,05)$, menunjukkan hipotesis diterima. Disimpulkan bahwa terdapat pengaruh penggunaan LKPD terhadap keterampilan berpikir kritis dan hasil belajar kelas XI IPA SMA Negeri 6 Maros materi pokok hidrolisis garam.
\end{abstract}

Kata kunci: LKPD, inkuiri terbimbing, hasil belajar, keterampilan berpikir kritis, hidrolisis garam.

\begin{abstract}
The research was quasi experiment which aims at examining the influence of utilizing LKPD on critical thinking skills and learning outcomeof student XI IPA at SMAN 6 in Maros on salt hydrolysis subject material. The research design was pretest treatmeant posttest. Samples were selected by employing random sampling and obtained student XI IPA 1 as A class and XI IPA 3 as B class. Data were analyzed by employing descriptive analysis and independent sample t-test. The result of descriptive analysis obtained the mean score of critical thinking skills and learning outcomes of A class was 72,76 and the B class was 56,90 with standard of deviation 15, 46 and 18,56 respectively. The data of the mean score of $\mathrm{N}$-gain of critical thinking skills indictor in A class was 0,625 which was in moderate category and $\mathrm{N}$-gain of learning outcomes was 0,70 which was in high category; whereas, the B class was 0,454 and 0,52 which was in moderate category. The result of hypothesis test with t-test at the level of significance, $\alpha=0,05$ obtained $t_{\text {count }} 3,22>t_{\text {table }} 2,02$ and significance $(0,003<0,05)$, indicated that the hypothesis was accepted. The conclusion that is influence of utilizing LKPD on critical thinking skills and learning outcomes of student XI IPA ata SMA Negeri in Maros on salt hydrolysis subject material.
\end{abstract}

Keywords: LKPD, Guided Inquiry, Learning Outcome, Critical Thinking Skills, Salt Hydrolysis. 


\section{PENDAHULUAN}

Dunia pendidikan di Indonesia masih dihadapi oleh lemahnya proses pembelajaran. Umumnya, ada beberapa faktor yang mempengaruhi proses pembelajaran seperti teknik mengajar pendidik, model; metode pembelajaran serta kemandirian peserta didik. Metode pembelajaran digunakan oleh pendidik untuk menciptakan lingkungan belajar dan mendasari aktivitas pendidik dan peserta didik (Ridwan, 2016).

Pada proses pembelajaran metode yang digunakan pendidik umumnya lebih cenderung mengarahkan peserta didik untuk menghafal konsep tanpa dituntut untuk memahami konsep yang diperoleh. Dengan demikian, kurangnya pemahaman peserta didik pada materi tersebut menyebabkan peserta didik kurang termotivasi dalam pembelajaran, sehingga menjadikan peserta didik kurang mengembangkan keterampilan berpikir kritis (Sanjaya, 2006). Berpikir kritis merupakan keterampilan dasar yang sangat dibutuhkan oleh peserta didik untuk memahami konsep-konsep. Keterampilan tersebut adalah proses intelektual dalam mengolah, menganalisis dan mengevaluasi informasi sehingga peserta didik dapat mengkonstruksikan pengetahuan dari berbagai displin ilmu untuk menemukan solusi dalam menghadapi masalah (Bassham, 2011; Budiastra, 2015; Paul and Elder, 2006).

Berdasarkan hasil wawancara dengan pendidik kimia dan observasi diSMA Negeri 6 Maros diperoleh informasi yaitu rendahnya motivasi belajar peserta didik dikarenakan proses pembelajaran kimia di SMA Negeri 6 Maros cenderung masih bersifat teacher centered dengan metode pembelajaran yang monoton, sehingga peserta didik kurang aktif dalam mengikuti pembelajaran. Guru sebagai informator yang berperan dominan dalam setiap kegiatan pembelajaran, seperti memberikan penjelasan materi dan latihanlatihan soal yang ada dalam lembar kerja peserta didik tanpa memberikan kesempatan kepada peserta didik untuk memecahkan masalah sendiri. Oleh karena itu, Peserta didik cenderung memiliki keterampilan mengingat dan menghafal konsep.Disisi lain, kurang maksimalnya penggunaan media pembelajaran dalam membantu penyampaian materi, serta kurang bervariasi dalam pemberian tugas. Lembar kerja peserta didik (LKPD) yang diberikan masih bersifat umum hanya memuat rangkuman materi dan latihan penyelesaian soal. Pendidik belum menerapkan LKPD yang mendukung peserta didik untuk mengembangkan keterampilan berpikir kritis. LKPD yang sering digunakan LKPD dari penerbit, padahal LKPD dapat dibuat sendiri oleh pendidik berdasarkan kebutuhan peserta didik sehingga dapat membangun konsep mereka sendiri dalam memecahkan masalah.

Hidrolisis garam merupakan reaksi ion-ion asam lemah dan basa lemah yang terurai dalam air. Kurangnya pemahaman peserta didik pada materi hidrolisis garam menyebabkan peserta didik kurang termotivasi dalam pembelajaran, sehingga menjadikan peserta didik kurang mengembangkan keterampilan berpikir kritis dan mempengaruhi hasil belajar mereka. Karena bagi peserta didik materi kimia yaitu salah satunya hidrolisis garam. Materi ini memuat konsep-konsep yang abstrak dan perhitungan sehingga peserta didik menganggap materi tersebut sulit untuk dipahami. Hal ini ditunjukkan dengan ratarata nilai pada materi hidrolisis garam peserta didik tahun ajaran 2016/2017 masih di bawah standar ketuntasan belajar. Kriteria Ketuntasan Minimal (KKM) dengan nilai 75 masih belum bisa dicapai oleh semua peserta didik. Terdapat 11 peserta didik dari 27 peserta didik yang nilainya kurang dari $\mathrm{KKM}$, dan hanya 16 peserta didik yang nilainya sudah mencapai KKM yang ditentukan. Data tersebut menunjukkan bahwa hanya $59 \%$ dari jumlah peserta didik yang belum mencapai KKM.

Menurut Halpern (2014), bahwa berpikir kritis juga merupakan suatu kemampuan kognitif dan strategi yang meningkatkan hasil yang diharapkan, 
berpikir yang bertujuan, beralasan dan berorientasi pada sasaran. Indikator berpikir kritis terdapat 5 apek yaitu: (1) memberikan penjelasan sederhana; (2) membangun keterampilan dasar; (3) member penjelasan lebih lanjut; (4) mengatur strategi dan taktik; dan (5) menyimpulkan (Ennis, 1985).

Hasil belajar merupakan gambaran tingkat penguasaan peserta didik berupa kemampuan intelektual, nilai sikap dan psikomotorik setelah proses pembelajaran berdasarkan tujuan pembelajaran yang dicapai. Hasil belajar kognitif dapat dilihat dari dimensi proses kognitifnya seperti mengingat $(\mathrm{C} 1)$, memahami $(C 2)$, menerapkan (C3), menganalisis C4), mengevaluasi (C5), dan mencipta (C6). Karakteristik hasil belajar kognitif tidak hanya berfokus pada pemahaman tetapi memiliki pengajaran secara timbal balik dari input dan output peserta didik setelah belajar, peserta didik mampu memiliki sikap inkuiri, serta memiliki kemampuan memecahkan masalah.

$$
\text { Inkuiri adalah pendekatan }
$$

pembelajaran dimana peserta didik menemukan dan menggunakan berbagai sumber informasi dan ide untuk meningkatkan pemahaman mereka tentang masalah, topik dan isu (Kuhlthau et al., 2015). Inkuiri terbimbing sebagai dasar untuk mendapatkan pengetahuan tentang beberapa konsep kimia dengan memanfaatkan bimbingan agar pendidik mampu memisahkan tingkat tertentu dalam memecahkan masalah (Lewicky, 1993 dalam Bilgin, 2009). Inkuiri terbimbing merupakan suatu cara yang efektif untuk membuat variasi suasana pola pembelajaran kelas.

Dalam upaya meningkatkan keterampilan berpikir kritis dan hasil belajar kimia peserta didik, perlu dilakukan inovasi pembelajaran dengan memperhatikan kesesuaian antara model, metode dan media pendukung dengan karakteristik materi yang disampaikan agar tujuan pembelajaran dapat tercapai seperti yang diharapkan. Salah satu media pembelajaran yang dapat digunakan adalah LKPD berbasis inkuiri terbimbing. LKPD disusun berdasarkan sintaks inkuiri terbimbing yaitu: 1) menyajikan masalah;2) merumuskan masalah; 3) mengumpulkan data/ merancang percobaan; 4) analisis data dan 5) membuat kesimpulan. LKPD ini mengandung unsur pengalaman belajar pokok yang diamanatkan oleh kurikulum 2013 yaitu, mengamati, menanya, mengumpulkan informasi, mengasosiasi dan mengkomunikasikan. LKPD berbasis inkuiri terbimbing dapat membantu pendidik untuk mendorong peserta didik lebih aktif dalam memecahkan masalah serta mengoptimalkan keterlibatan atau aktivitas peserta didik dalam pembelajaran. LKPD berbasis inkuiri terbimbing yang digunakan dalam penelitian ini adalah LKPD yang telah dikembangkan para peneliti sebelumnya pada beberapa materi pembelajaran kimia.

Hal ini didukung oleh beberapa penelitian sebelumnya. Annafi (2016) mengungkapkan LKPD berbasis inkuiri terbimbing dapat meningkatkan hasil belajar peserta didik pada kelas eksperimen dibandingkan kelas kontrol. Peserta didik kelas eksperimen memiliki antusias yang baik dalam pembelajaran menggunakan LKPD berbasis inkuiri terbimbing. Nurfajariyah,. et.al (2016) juga mengungkapkan pembelajaran inkuiri terbimbing meningkatkan kemampuan berpikir kritis.

Berdasarkan latar belakang tersebut, maka peneliti mengangkat judul " Pengaruh Penggunaan LKPD terhadap Keterampilan Berpikir Kritis dan Hasil Belajar Peserta Didik Kelas XI IPA SMA Negeri 6 Maros (Studi Materi Pokok Hidrolisis Garam). Adapun tujuan dari penelitian ini adalah untuk mengetahui: (1) Pengaruh penggunaan LKPD terhadap keterampilan berpikir kritis; (2) Pengaruh penggunaan LKPD terhadap hasil belajar. 


\section{METODE PENELITIAN}

Jenis penelitian adalah penelitian eksperimen semu) yang mengikuti bentuk pretest treatment posstest design yang disajikan dalam Tabel 2. Penelitian ini dilaksanakan pada semester genap tahun ajaran 20172018 di SMA Negeri 6 Maros.

Tabel 1. Desain Penelitian

\begin{tabular}{|c|c|c|c|}
\hline $\mathrm{R}$ & $O_{1}$ & $X_{1}$ & $O_{2}$ \\
\hline $\mathrm{R}$ & $O_{3}$ & $X_{2}$ & $O_{4}$ \\
\hline
\end{tabular}

(Sugiyono, 2016)

Keterangan:

$\mathrm{O}_{1}$ : Pretest pada kelas A

$\mathrm{O}_{2}$ : Postest pada kelas A

$\mathrm{X}_{1}$ : Menggunakan LKPD berbasis inkuiri terbimbing

$\mathrm{X}_{2}$ : Menggunakan LKPD biasa

$\mathrm{O}_{1}$ : Pretest pada kelas B

$\mathrm{O}_{2}$ : Postest pada kelas $\mathrm{B}$

Variabel pada penelitian ini terdiri dari variabel bebas (independent) dan variable terikat (dependent).Variabel bebas dalam penilitian ini terdiri dari LKPD berbasis inkuiri terbimbing dan LKPD biasa.Variabel terikat dalam penelitian ini adalah adalah keterampilan berpikir kritis dan hasil belajar kimia.

Populasi dalam penelitian ini adalah kelas XI SMA 6 Maros tahun pelajaran 2017/2018 terdiri dari tiga kelas dengan jumlah 68 peserta didik. Sampel penelitian ini dilakukan dengan cara random sampling. Kelas XI IPA 1 sebagai kelas A dan kelas XI $\mathrm{IPA}_{3}$ sebagai kelas B. Instrument dalam penelitian ini adalah tes tertulis berupa essay digunakan untuk mengukur keterampilan berpikir kritis dan hasil belajar.

Teknik analisis data menggunakan analisis deskriptif dan inferensial. Untuk mengetahui adanya peningkatan keterampilan berpikir kritis dan hasil belajar peserta didik antara kelas A dan kelas B digunakan analisis normalized gain $(N$ gain). Menurut Hake (1999) dapat digunakan rumus:

$$
\langle g\rangle=\frac{\text { Skor postes }- \text { skor pretest }}{\text { skor maksimal-skor pretes }}
$$

Tabel 2. Kriteria nilai gain score ternormalisasi

\begin{tabular}{cc}
\hline Nilai $\langle g\rangle$ & Kriteria \\
$\langle g\rangle \geq 0,7$ & Tinggi \\
$0,7\langle g\rangle \geq 0,3$ & Sedang \\
$\langle g\rangle\langle 0,3$ & Rendah \\
\hline (Hake : 1999) & \\
Data yang & diperoleh kemudian
\end{tabular}
dianalisis dengan uji Independent Sample TTest, terlebih dahulu diuji dengan uji normalitas dan uji homogenitas. Uji hipotesis digunakan untuk mengetahui pengaruh penggunaan LKPD terhadap keterampilan berpikir kritis dan hasil belajar peserta didik kelas XI IPA SMA Negeri 6 Maros.

Uji hipotesis berpedoman berdasarkan nilai signifikansi:

(1) Jika nilai signifikansi $>0,05$, maka $\mathrm{H}_{0}$ diterima;

(2) Jika nilai signifikansi $<0,05$, maka $\mathrm{H}_{0}$ ditolak.

\section{HASIL DAN PEMBAHASAN}

\section{Hasil Penelitian}

\section{Deskripsi Data Keterampilan Berpikir Kritis}

Dari penelitian yang telah dilakukan pada kedua kelas yaitu kelas A (XI IPA 1) dan kelas B (XI IPA 3), diperoleh data tentang keterampilan berpikir kritis peserta didik berdasarkan kategori dan nilai rata-rata $N$-gain pada tiap indikator, dapat dilihat pada Tabel 3 dan 4 .

Tabel 3.Kategori keterampilan berpikir kritis peserta didik kelas A dan kelas B

\begin{tabular}{cccccc}
\hline & Prese & \multicolumn{2}{c}{ Kelas A } & \multicolumn{2}{c}{ Kelas B } \\
\cline { 3 - 6 } Kategori & $\begin{array}{c}\text { ntase } \\
(\boldsymbol{\%})\end{array}$ & $\begin{array}{c}\text { Frek } \\
\text { uensi }\end{array}$ & $\begin{array}{c}\text { Persen } \\
\text { tase } \\
(\boldsymbol{\%})\end{array}$ & $\begin{array}{c}\text { Freku } \\
\text { ensi }\end{array}$ & $\begin{array}{c}\text { Persen } \\
\text { tase } \\
(\boldsymbol{\%})\end{array}$ \\
\hline Tinggi & $>80$ & 7 & 33,33 & 5 & 23,81 \\
\hline Sedang & $60-80$ & 11 & 52,38 & 4 & 19,05 \\
\hline Rendah & $<60$ & 3 & 14,29 & 12 & 57,14 \\
\hline \multicolumn{2}{c}{ Jumlah } & 21 & 100 & 21 & 100 \\
\hline
\end{tabular}

Tabel 4. Rata- rata $N$-gain setiap aspek keterampilan berpikir kritis pada kelas A dan kelas B

\begin{tabular}{lll}
\hline No & Indikator & $N$-gain \\
\hline
\end{tabular}




\begin{tabular}{llcc}
\hline & \begin{tabular}{c}
\multicolumn{1}{c}{ Kritis } \\
Keterampilan Berpikir
\end{tabular} & Kelas A & Kelas B \\
\hline 1. & $\begin{array}{l}\text { Memberikan } \\
\text { penjelasan sederhana }\end{array}$ & 0,522 & 0,340 \\
\hline 2. & $\begin{array}{l}\text { Membangun } \\
\text { keterampilan dasar }\end{array}$ & 0,609 & 0,466 \\
\hline & $\begin{array}{l}\text { Memberikan } \\
\text { penjelasan } \\
\text { lanjut }\end{array}$ & 0,629 & 0,546 \\
\hline Mebih & $\begin{array}{l}\text { Mengatur strategi dan } \\
\text { taktik }\end{array}$ & 0,736 & 0,520 \\
\hline 5. & Menyimpulkan & 0,628 & 0,400 \\
\hline & Rata-rata & 0,625 & 0,454 \\
\hline
\end{tabular}

\section{Deskripsi Data Hasil Belajar}

Berdasarkan hasil belajar peserta didik kelas A (XI IPA 1) dan kelas B (XI IPA 3) yang dibelajarkan menggunakan LKPD berbasis inkuiri terbimbing dan LKPD biasa diperoleh hasil analisis deskriptif yang menunjukkan hasil belajar kognitif peserta didik pada materi hidrolisis garam dapat dilihat pada Tabel 5 dan nilai $\mathrm{N}$-gain hasil belajar peserta didik pada Tabel 6.

Tabel 5. Nilai deskriptif keterampilan berpikir kritis peserta didik kelas A dan kelas B

\begin{tabular}{ccc}
\hline \multirow{2}{*}{ Statistik Deskriptif } & \multicolumn{2}{c}{ Nilai Statistik } \\
\cline { 2 - 3 } & Kelas A & Kelas B \\
\hline Jumlah Sampel $(n)$ & 21 & 21 \\
\hline Nilai Tertinggi & 100 & 90 \\
\hline Nilai Terendah & 35 & 25 \\
\hline Rata-Rata & 72,76 & 56,48 \\
\hline Standar Deviasi & 15,17 & 18,80 \\
\hline
\end{tabular}

Tabel 6. Data $N$-gainpeserta didik kelas A dan kelas B

\begin{tabular}{|c|c|c|c|c|}
\hline \multirow{2}{*}{ Kelas } & \multicolumn{2}{|c|}{ Nilai Rata-rata } & \multirow{2}{*}{$\begin{array}{c}N- \\
\text { gain }\end{array}$} & \multirow{2}{*}{ Kategori } \\
\hline & Pretest & Posttest & & \\
\hline KelasA & 8,62 & 72,76 & 0,70 & Tinggi \\
\hline Kelas B & 8,76 & 56,48 & 0,52 & Sedang \\
\hline
\end{tabular}

\section{Hasil Pengujian Hipotesis}

Sebelum melakukan pengujian analisis hipotesis, maka terlebih dahulu dilakukan pengujian dasar analisis berupa uji normalitas dan dan uji homogenitas agar diketahui analisis yang akan digunakan untuk pengujian hipotesis, data disajikan untuk uji normalitas dan uji homogenitas padaTabel 7 dan hasil pada Tabel 8 .

Tabel 7. Hasil uji normalitas pada kelas A dan kelas B

\begin{tabular}{ccccc}
\hline & & \multicolumn{3}{c}{ Shapiro-Wilk } \\
\cline { 3 - 5 } & Kelas & Statistik & df & Signifikansi \\
\hline \multirow{2}{*}{-gain } & Kelas A & 0.923 & 21 & 0.100 \\
\cline { 2 - 5 } & Kelas B & 0.963 & 21 & 0.571 \\
\hline
\end{tabular}

Berdasarkan Tabel 7 dapat diketahui bahwa nilai signifikansi $>\alpha=0,05$, untuk kelas A diperoleh sebesar 0,100 , sedangkan kelas B dengan nilai sebesar 0,571. Hal ini menunjukkan bahwa kedua kelas terdistribusi normal.

Tabel 8.Hasil Uji homogenitas untuk $N$-gain

\begin{tabular}{cccc}
\hline Levene Statistic & df1 & df2 & Signifikansi \\
\hline 2.323 & 1 & 40 & 0.135 \\
\hline
\end{tabular}

Berdasarkan Tabel 8 dapat diketahui yaitu $F_{\text {hitung }}<F_{\text {tabel }}$ dan nilai signifikansi $>\alpha=0,05$, diperoleh nilai signifikansi sebesar 0,135. Hal ini dapat disimpulkan bahwa data berasal dari variansi yang homogen.

Setelah dilakukan uji normalitas dan uji homegenitas, diperoleh data dari kedua kelas terdistribusi normal dan memiliki varians yang homogen sehingga dapat dilakukan pengujian hipotesis pada Tabel 9.

Tabel 9. Hasil Uji t

\begin{tabular}{c|cccc}
\hline & Kelas & $\mathrm{t}$ & df & $\begin{array}{c}\text { Sig. (2- } \\
\text { tailed) }\end{array}$ \\
\hline \multirow{2}{*}{$\begin{array}{c}\text { N- } \\
\text { gain }\end{array}$} & Kelas A & 3.226 & 40 & .003 \\
\cline { 2 - 5 } & Kelas B & 3.226 & 37.79 & .003 \\
\hline
\end{tabular}

Dari Tabel 9. terlihat bahwa nilai $t_{\text {hitung }}>t_{\text {Tabel }}$ dan nilai signifikansi diperoleh sebesar 0,003, maka disimpulkan $\mathrm{H}_{0}$ ditolak dan $\mathrm{H}_{1}$ diterima pada taraf signifikansi 0,05. Hal ini menunjukkan bahwa penggunaan LKPD berpengaruh terhadap keterampilan berpikir kritis dan hasil belajar kelas XI IPA SMANegeri 6 Maros. 
2. Pembahasan Hasil Penelitian

a. Pengaruh penggunaan LKPD terhadap keterampilan berpikir kritis

Hasil dan analisis data penelitian ini menunjukkan bahwa nilai rata-rata peserta didik pada kelas A yang diajarkan menggunakan LKPD berbasis inkuiri terbimbing lebih tinggi daripada kelas $\mathrm{B}$ yang menggunakan LKPD biasa. Hal ini dikarenakan peserta didik terlibat secara aktif dalam kegiatan kelas, sehingga peserta didik tidak bosan dan mudah menyerap apa yang dipelajari (Chebi, 2012).

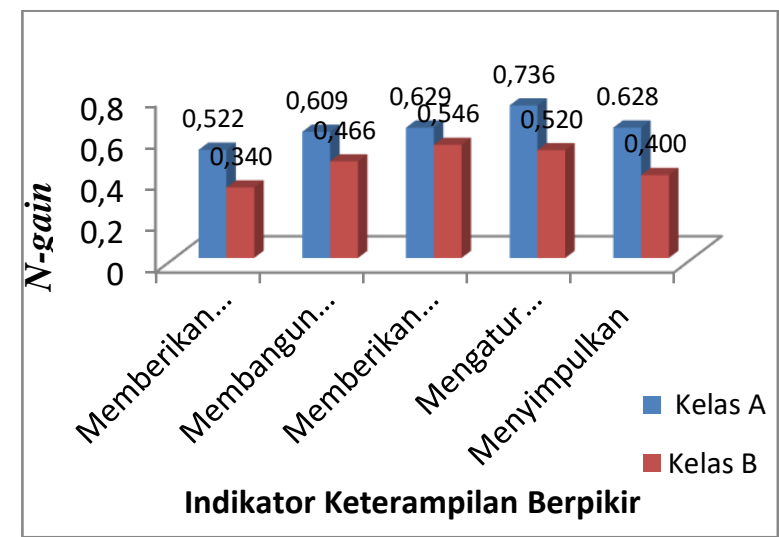

Gambar 1. Rata-rata $N$-gain tiap indikator keterampilan berpikir kritis kelas A dan kelas B

Berdasarkan gambar 1, diketahui bahwa terjadi peningkatan rata-rata $N$-gain pada tiap indikator keterampilan berpikir kritis yang beragam. Pada kelima indikator keterampilan berpikir kritis yang diujikan, peningkatan yang signifikan terdapat pada indikator mengatur strategi dan taktik. Pada indikator mengatur strategi dan taktik memiliki kategori tinggi. Hal ini dikarenakan sebagian besar peserta didik pada kelas A telah mampu memecahkan masalah perhitungan dengan menggunakan rumus yang mereka pahami dibandingkan kelas B. Peserta didik dapat menentukan dengan tindakan yang tepat dalam menganalisis masalah sampai dengan mengidentifikasinya. Hal ini sangat mempengaruhi keterampilan berpikir kritis. Selain itu, peserta didik aktif dalam mencari informasi dari berbagai sumber belajar baik dari buku-buku maupun internet sehingga memudahkan mereka dalam menjawab soal LKPD.

Indikator memberi penjelasan sederhana, membangun keterampilan dasar, memberi penjelasan lebih lanjut dan menyimpulkan berada pada ketegori sedang. Indikator menyimpulkan meskipun mengalami peningkatan namun nilai ratarata yang diperoleh masih rendah dibandingkan indikator lainnya. Disebabkan karena peserta didik tidak menuliskan kesimpulannya walaupun jawabannya benar, dan kalaupun menjawab semua namun hasil perhitungannya salah sehingga pada saat menyimpulkan menjadi salah pula, pada instrument penelitian terdiri dari sebagian besar soal perhitungan dimana pengajaran yang dilaksanakan lebih mengarah kepada konsep-konsep.

Perbandingan kriteria berpikir kritis dengan kategori tinggi, sedang dan rendah antara kelas A dan kelas B menunjukkan bahwa pada kelas A lebih baik daripada kelas B. Dari hasil presentase keterampilan berpikir kritis peserta didik dapat disimpulkan bahwa penggunaan LKPD berbasis inkuiri terbimbing memberikan pengaruh yang lebih baik daripada LKPD biasa terhadap keterampilan berpikir kritis peserta didik. Anggareni, dkk (2013) juga menyebutkan bahwa berdasarkan sintaks dalam pembelajaran inkuiri terbimbing sangat mendukung proses berpikir tingkat tinggi.

Hasil pengujian hipotesis menunjukkan bahwa nilai $t_{\text {hitung }}>t_{\text {tabel }}$ dan nilai signifikan (2-tailed) adalah (3,22> $0,05)$ dan $(0,003<0,05)$ dengan nilai $\alpha=$ 0,05 diketahui bahwa signifikansi (sig.) $<\alpha$. Artinya, $\mathrm{H}_{0}$ ditolak dan $\mathrm{H}_{1}$ diterima, terdapat pengaruh penggunaan LKPD terhadap hasil belajar peserta didik kelas XI IPA SMA Negeri 6 Maros pada materi hidrolisis garam

\section{b. Pengaruh penggunaan LKPD terhadap hasil belajar}

Data hasil penelitian dan analisis data diperoleh bahwa peserta didik yang dibelajarkan menggunakan LKPD berbasis inkuiri terbimbing memiliki hasil belajar 
kimia yang lebih baik daripada peserta didik yang dibelajarkan dengan menggunakan LKPD biasa. Artinya, penggunaan LKPD berbasis inkuiri terbimbing memberikan pengaruh terhadap hasil belajar peserta didik. Hal ini dibuktikan dengan rata-rata $\mathrm{N}$ gain hasil belajar peserta didik pada kelas A sebesar 0,70 dengan kategori tinggi sedangkan kelas B sebesar 0,52 dengan kategori sedang. Peningkatan hasil belajar dengan menggunakan LKPD berbasis inkuiri terbimbing menghadapkan peserta didik kepada pengalaman kongkrit sehingga peserta didik belajar secara aktif, dimana mereka didorong untuk mengambil inisiatif dalam usaha memecahkan masalah, mengambil keputusan dan mengembangkan keterampilan praktikum.

LKPD berbasis inkuiri terbimbing disusun berdasarkan sintak inkuiri terbimbing yaitu mengidentifikasi masalah, hipotesis, mengumpulkan data, menganalisis dan evaluasi (Hanson, 2005). Penggunaan LKPD berbasis inkuiri terbimbing, peserta didik dapat menemukan konsep setelah mampu mengidentifikasi masalah dan berhipotesis. Dalam menjawab dugaan sementara inilah peserta didik berdiskusi sesame teman kelompok untuk memecahkan masalah dan guru dapat mengatur serta membimbing jalannya diskusi. Pada proses pembelajaran dikelas dengan menggunakan LKPD berbasis inkuiri terbimbing dapat meningkatkan antusias peserta didik dalam mencari dan memecahkan masalah.

Hasil pengujian hipotesis menunjukkan bahwa nilai $t_{\text {hitung }}>t_{\text {tabel }}$ dan nilai signifikan (2-tailed) adalah (3,22 > $0,05)$ dan $(0,003<0,05)$ dengan nilai $\alpha=$ 0,05 diketahui bahwa signifikansi (sig.) $<\alpha$. Artinya, $\mathrm{H}_{0}$ ditolak dan $\mathrm{H}_{1}$ diterima, terdapat pengaruh penggunaan LKPD terhadap hasil belajar peserta didik kelas XI IPA SMA Negeri 6 Maros pada materi hidrolisis garam.

Penelitian sebelumnya yang dilakukan oleh (Rudi Kurniawan, 2016) dan (Iryani, dkk, 2016) yang menyatakan bahwa penggunaan LKPD berbasis inkuiri terbimbing berpengaruh signifikan terhadap hasil belajar peserta didik. Penelitian lain (Arwi Rinaldo, 2017) dan (I Putu Yudiarta, dkk, 2014) yang menyatakan bahwa penggunaan LKPD berbasis inkuiri terbimbing dapat meningkatkan keterampilan berpikir kritis dibandingkan penggunaan LKPD biasa. Dengan demikian, hasil penelitian sebelumnya tidak jauh berbeda dengan hasil penelitian ini bahwa terdapat pengaruh penggunaan LKPD terhadap keterampilan berpikir kritis dan hasil belajar peserta didik kelas XI IPA SMA Negeri 6 Maros pada materi hidrolisis garam.

\section{SIMPULAN DAN SARAN}

Berdasarkan hasil penelitian dan pembahasan maka dapat disimpulkan penggunaan LKPD berpengaruh terhadap keterampilan berpikir kritis dan hasil belajar peserta didik kelas XI IPA SMA Negeri 6 Maros pada materi pokok hidrolisis garam. Hal ini ditunjukkan dengan hasil uji hipotesis diperoleh nilai thitung 3,22> $t_{\text {tabel }}$ 2,02 dan signifikansi $(0,003<0,05)$ sehingga hipotesis $\left(\mathrm{H}_{1}\right)$ diterima.

Adapun saran:

1. Bagi pendidik, LKPD berbasis inkuiri terbimbing dapat dijadikan salah satu alternatif pembelajaran di kelas untuk meningkatkan keterampilan berpikir kritis.

2. Bagi peneliti selanjutnya, dapat menjadi referensi oleh peneliti lain untuk diterapkan atau dikembangkan dengan penelitian berikutnya yang sejenis pada materi yang berbeda.

\section{DAFTAR RUJUKAN}

Arsyad, Azhar. 2014. Media Pembelajaran(Edisi Revisi). Jakarta: PT Raja Grafindo Persada.

Anggareni, N W., N.P. Ristianti, dan N.L. P. M, Widiyanti. 2013. Implementasi Strategi Pembelajaran Inkuiri terhadap Kemampuan Berpikir Kritis 
dan Pemahaman Konsep IPA Siswa SMP. Journal (Volume 3 Tahun 2013) Program Pascasarjana Universitas Pendidikan Ganesha. Singaraja.

Annafi, Nurfidianty. 2016. Pengaruh Penerapan LKPD Berbasis Inkuiri Terbimbing di MAN 1 Kota Bima. Journal of EST, Volume 2 Nomor 2 Agustus hal. 98-104. P-ISSN : 24601497, e- ISSN: 2477-3840.

Bassham, G., 2011. Critical thinking: A student's introduction. Mc Graw-Hill Connect Learn Succeed.

Bilgin, Ibrahim. 2009. The effects of guide inquiry instruction incorporating a cooperative learning approach on university students' achievement of acid and bases concepts and attitude toward guided inquiry instruction. Scientific Research and Essay Vol. 4 (10), pp. 1038-1046, ISSN 19922248@ 2009 Academic Journals. Mustafa Kemal University Hatay Turkey.

Budiastra, A.A., 2015. The development of measurement tools for senior high school students' critical thinking skills in chemistry. Int. J. Adv. Res. Manag. Soc. Sci. 4, 108-121.

Chebii, R., W. Samwuel, dan K. Joel. 2012. Effects of Science Process Skills Mastery Learning Approach on Students' Acquisition of Selected Chemistry Practical Skills in School.Scientific Research, 3(8):1291-1296.

Ennis, R.H. 1985. Test That Could be Called Critical Thinking Tests. In A. L. Costa. Developing Mind. Alexandria, Virginia: Association for Supervition and Curriculum Development.

Hanson, David .M. 2005. Instructor's Guided to Process- Oriented Guided Inquiry Learning. Lisle, IL: Pacific Crest.

Hake. 1999. Interactive-engangement vs traditional methods: a six-thosandstudent survey of mechanics test data for intruductory physics courses.
American Journal of Physics, 66(1), 64-74

Halpern, Diane F. 2014. Thougt and Knowledge An Inbtroduction to Critical Thinking Fifth Edition. New York: Psycology Press

Iryani, Mawardi, Andromeda.2016. Pengaruh Penggunaan LKS Berbasis Inkuiri Terbimbing Terhadap Hasil Belajar Siswa untuk Materi Koloid Kelas XI SMAN 1 Batusangkar.Jurnal Eksata. Vol I Tahun XVII Februari 2016.

Kuhlthau, C.C., Maniotes,L.K, dan Caspari, A. K. 2015. Guided Inquiry: Learning in the $21^{\text {th }}$ century. London: Libraries Unlimite.

Kurniawan, Rudi. 2016. Pengaruh Penggunaan LKS Berbasis Guided Inquiry terhadap Hasil Belajar Fisika Siswa kelas X MIPA SMA. Jurnal Riset Fisika Edukasi Sains Vol 2, No.2. (2016). E- ISSN : 2503-3425, P- ISSN : 2407-3563.

Nur Fajariyah,. Budi Utami,. Haryono. 2016. Penerapan Model Pembelajaran Inkuiri Terbimbing untuk Meningkatkan Kemampuan Berpikir Kritis dan Prestasi Belajar pada Materi Kelarutan dan Hasil Kali Kelarutan Siswa Kelas XI SMA Al Islam 1 Surakarta Tahun Ajaran 2014/ 2015. Jurnal Pendidikan Kimia . Volume 5 No. 2 Tahun 2016: 89-97. ISSN 2337-9995

Paul, R., Elder, L., 2006. Critical thinking competency standards. Foundation for Critical Thinking.

Sani, Ridwan A. 2013. Inovasi Pembelajaran. Jakarta: PT Bumi Aksara.

Sugiyono. 2016. Metode Penelitian Pendidikan (Pendekatan Kuantitatif, Kualitatif, dan R\&D). Bandung: Alfabeta.

Rinaldo Arwi,. Chandra Ertikanto, Feriansyah Sesunan.2017. Pengaruh Lembar Kerja Siswa Berbasis Inkuiri Terbimbing Topik Pembiasan Cahaya terhadap Kemampuan 
Berpikir Kritis. Jurnal FKIP Universitas Lampung.

Trianto. 2007. Model pembelajaran Terpadu dalam Teori dan Praktek. Jakarta: Prestasi Pustaka.

Yudiarta, I Putu,.Tri Jalmo,. Rini Rita T. Marpaung. 2014. Penggunaan Lembar Kerja Siswa Berbasis Inkuiri Terhadap Keterampilan Berpikir Kritis. 